\section{Plug fate in the copulatory behavior of rats*}

\author{
DIRK W. MOSIG and DONALD A. DEWSBURY $\dagger$ \\ University of Florida, Gainesville, Fla. 32601
}

Normative data on the fate of ejaculatory plugs were collected following a total of 162 ejaculations attained by 18 male rats each given three tests. Sixty-nine percent of the plugs were dislodged, $82 \%$ of these after three or fewer intromissions. Males ate a total of $65 \%$ of the plugs, whereas females ate none. More than half of the plugs consumed were consumed between the time of dislodging and the next intromission. Plug consumption is a behavioral pattern appropriate for further study.

The purpose of this research was to collect normative data regarding plug consumption during the copulatory behavior of rats. Although it is well-known that male rats produce ejaculatory plugs during both spontaneous emissions and copulation with estrous females, there has been little interest until recently in the eventual fate of deposited plugs. The discovery that spontaneously emitted plugs could be recovered beneath wire-mesh cages if rats were muzzled or girdled led to much interest in the fate of such plugs. It was found that, unless restrained from doing so, male rats consume most spontaneously emitted plugs (Orbach, 1961; Beach, Westbrook, \& Clemens, 1966; Orbach, Miller, Billimoria, \& Solhkhah, 1967).

The fate of vaginally deposited plugs has received less attention. As most investigations of copulatory behavior are conducted with the rats in some light-colored, absorbent litter material, it appeared possible that dislodged plugs might never be noticed by an $O$. Therefore, a series of preliminary tests was conducted in glass-bottomed cages in order that plugs might readily be observed. It became apparent that plugs frequently were dislodged and eaten, and that normative data were needed. A series of tests was conducted in order to provide such data.

The present data were collected independently of Lisk's (1969) discussion of plug fate and generally provide more detailed data than appear in that study. Comparisons of data from the two studies will be made where possible.

\section{METHOD}

The Ss were 18 male Long-Evans rats approximately 200 days of age at the start of data collection. They were sexually experienced, having received three prior

*This research was supported by Grant GB-1294l from the National Science Foundation. Hormones were generously provided by Dr. Preston L. Perlman of the Schering Corporation, Bloomfield, New Jersey.

tPlease address requests for reprints to D. A. Dewsbury, Department of Psychology, 109 Building $\mathrm{L}$, University of Florida, Gainesville, Florida 32601 . tests of copulatory behavior and extensive handling. They were mated with 36 females of the same age and strain.

Tests were conducted in a specially constructed ventral-view test arena. A 78-cm-square piece of glass was mounted in the top of a $90 \times 80 \times 72 \mathrm{~cm}$ flat-black wood box. The front of the box was open. A $78 \times 81 \mathrm{~cm}$ mirror was mounted at an angle of $20 \mathrm{deg}$ inside the box. A cylindrical piece of Plexiglas, $81 \mathrm{~cm}$ in diam and $66 \mathrm{~cm}$ high, was placed on top of the box. Light was provided by a single $40-\mathrm{W}$ bulb mounted below and in front of the box. With rats copulating inside the Plexiglas cylinder on the glass, the $\mathrm{O}$ had a clear view from both lateral and ventral aspects of all copulations and of all dislodged plugs.

The rats were maintained on a reversed 12-12 light-dark cycle, with the lights coming on at 10:00 p.m. and going off at 10:00 a.m. Tests were initiated $3 \mathrm{~h}$ after the beginning of the dark phase.

Females received an intramuscular injection of $0.1 \mathrm{mg}$ estradiol benzoate 3 days before testing and an injection of $1.0 \mathrm{mg}$ progesterone on the morning of testing. All injected females were tested for receptivity with nonexperimental males prior to each test and only receptive females were used in tests.

Males were placed in the arena and given $5 \mathrm{~min}$ to explore it. Tests began with the introduction of the receptive female. If copulation was not initiated with in $15 \mathrm{~min}$, the test was terminated. If copulation was initiated, the test was continued until the occurrence of the fourth ejaculation. Each male was tested until he had completed three successful tests. An interval of at least 2 weeks was allowed between successive successful tests for individual males.

Standard measures of copulatory behavior were determined (Beach \& Jordan, 1956). Copulatory behavior in rats consists of bouts of mounts (with pelvic thrusting but without vaginal intromission), intromissions (with vagina] penetration), and ejaculations (with sperm emission), which are separated from each other by refractory periods. Bouts of copulatory behavior are termed series, are always terminated by an ejaculation, and are characterized by the number of mounts and intromissions in the series and by the total elapsed time from the first intromission to the terminal ejaculation (ejaculation latency). The refractory periods separating series are termed postejaculatory intervals. The occurrences of mounts, intromissions, and ejaculations were recorded on an Esterline-Angus operations recorder so that these measures could be determined. Occurrences of the dislodging and of the eating of plugs also were noted on the recorder so that the exact time of each event could be determined. Supplementary notes clarified ambiguous cases, such as dislodging of multiple plugs

\section{RESULTS}

All $18 \mathrm{Ss}$ completed three successful tests. Half of the animals completed these with no negative tests, while the remaining animals completed the tests after a mean of 2.3 negative tests (range $=1-4$ ). A total of 216 ejaculations occurred during the 54 tests conducted.

As tests were terminated immediately after the fourth ejaculation, only those plugs associated with the first three ejaculations (total $=162$ ) could have been dislodged during the test. There were a total of 112 plugs dislodged in a total of 103 instances of plug dislodgment. This was due to seven instances of two plugs being simultaneously dislodged and one instance of three plugs being simultaneously dislodged. There was no way to tell whether these were separate plugs dislodged at the same time or a single plug that had been broken. If the former, a total of $69 \%$ of all possible plugs were dislodged. If the latter, the figure would be reduced to $64 \%$. As plugs had to be eaten separately, they will be considered as separate.

Of the 112 plugs dislodged, $14 \%$ (16) were dislodged on the first intromission following the ejaculation, $37 \%$ (41) were dislodged after the second intromission, $21 \%$ (24) were dislodged after the third intromission, and the remaining $28 \%$ (31) were dislodged at a later time. Thus a total of $82 \%$ of the dislodged plugs ( $50 \%$ of all plugs delivered) were dislodged within three intromissions of the preceding ejaculation.

The males ate a total of 73 of the 112 dislodged plugs (65\%). Although females were observed occasionally to pick up plugs and manipulate them with their forepaws, they never ate a plug. A total of 41 plugs (56\% of those eaten) were consumed immediately (i.e., before the next intromission). Of the 32 plugs that 
were consumed at a later time, $25 \%$ were eaten later in the same series; $41 \%$ were eaten during the next postejaculatory interval; $22 \%$ were eaten during the next series; $6 \%$ were eaten during the next postejaculatory interval; and $6 \%$ during the following series.

Each of the 18 males dislodged at least one plug. Fifteen of the rats ate at least one plug, while the remaining animals failed to eat any of their plugs. Five of the rats that ate some of their plugs ate none of them immediately. Six of the rats ate at least two-thirds of their plugs immediately.

Although there was some fluctuation in the various parameters, there appeared no major changes in behavior over the tests.

The behavior associated with immediate plug consumption was quite stereotyped. In attaining intromission, male rats execute several short thrusts, one deep thrust, and a rapid dismount. The female holds her lordosis posture briefly and then darts away. The male remains where he lands after the dismount to engage in a bout of genital grooming. Frequently this is followed by bouts of grooming other parts of the body, including grooming of the head with the forepaws. Because of the stationary posture of the male after dismounting and the darting away by the female, the plug frequently lies directly below the male's mouth when he completes genital grooming. Typically, he sweeps up the plug in a forepaw and consumes it rapidly with minimal excess movement. As the behavior appears executed with great speed and facility, it is readily confused with general grooming if the plug is not apparent. The behavior associated with consumption of plugs at later times is less stereotyped. Typically, the male encounters the plug while exploring the apparatus and simply stops to eat it.

\section{DISCUSSION}

These data provide normative information regarding generally neglected aspects of copulatory behavior of male rats, plug dislodgment and consumption. They reveal a high frequency of plug dislodgement in multiple-ejaculation tests. Males are quite likely to eat plugs, whereas females are not. The speed and facility with which plugs may be eaten make it easy for the $\mathrm{O}$ using standard test arenas to completely miss the behavior.

These data and those of Lisk (1969) are in striking agreement with respect to the dislodging of plugs. In both studies, $82 \%$ of the dislodged plugs were dislodged within three intromissions. Whereas $37 \%$ of the dislodged plugs in the present study were eaten immediately, the figure was just $13 \%$ in the Lisk study. This difference may be attributable to any of a large number of procedural differences between the two studies. The present test situation appears more representative of the testing situation used in many behavioral laboratories, whereas the Lisk situation is more representative of prolonged pairing and familiarity in a single stable pair. There are no other comparable data between the two studies.

Some investigators have attempted to infer the number of ejaculations in a mating test from the number of plugs deposited on paper beneath wire-mesh cages (Lisk, 1966a, b). Lisk (1969) concludes that it is possible to obtain an estimate of the time at which mating occurs and the duration of the period of copulatory activity from frequent checks of plugs. While this appears true, the facts that some plugs are never dislodged and that many are eaten indicate that this may not provide a particularly sensitive measure of copulatory behavior. It will be important to determine the frequency with which plugs get trapped in mesh cages and therefore are accessible to the male for consumption. While plug deposition may be a useful general indicant of copulatory activity, the many possibilities for systematic errors due to dislodgment, consumption, and individual differences therein, indicate that this procedure cannot be regarded as a substitute for behavioral observation.

Plug consumption is revealed as a behavioral pattern appropriate for further analyses. For example, there has been much recent interest in the effects of manipulation of early hormone environment in various aspects of sex differences in adult reproductive behavior (Whalen, 1968). Such manipulations also affect taste preferences (Wade \& Zucker, 1969). The effects of manipulation of the early hormonal environment on the striking sexual dimorphism in plug consumption would be of interest. Also interesting would be a study of the effects of neural intervention on plug consumption. This would provide an empirical test of the proposal of Beach (1966) that mammillary lesions may alter plug consumption rather than copulatory behavior. Again, whereas septal lesions do not alter copulatory behavior (Goodman, Bunnell, Dewsbury, \& Boland, 1969), they do affect the frequency with which plugs are found beneath the male's cage (Clody \& Carlton, 1969). The latter effect could be due either to a change in the number of plugs produced or to a change in plug consumption (Clody \& Carlton, 1969). The possibility that females might consume plugs when tested in postpartum estrus, near the period where placentaphagia is common, merits testing. Finally, comparative studies in different species would be of interest. Studies in our laboratory have revealed similar plug consumption in montane voles, Microtus montanus.

REFERENCES

BEACH, F. A. Sexual behavior in the male rat. Science, 1966, 153, 769-770.

BEACH, F. A., \& JORDAN, L. Sexual exhaustion and recovery in the male rat. Quarterly Journal of Experimental Psychology, 1956, 7, 121-133.

BEACH, F. A., WESTBROOK, W. H., \& CLEMENS, L. G. Comparisons of the ejaculatory response in men and animals. Psychosomatic Medicine, 1966, 28, 749-763.

CLODY, D. E., \& CARLTON, P. L. Behaviora effects of lesions of the medial septum of rats. Journal of Comparative \& Physiological Psychology, 1969, 67, 344-351.

GOODMAN, E. D., BUNNELI, B. N, DEWSBURY, D. A., \& BOLAND, B. Septal lesions and male rat copulatory behavior. Psychonomic Science, 1969, 16, 123-124.

LISK, R. D. Inhibitory centers in sexual behavior in the male rat. Science, $1966 \mathrm{a}, 152,669-670$.

LISK, R. D. Increased sexual behavior in the male rat following lesions in the mammallary region. Journal of Experimental Zoology, 1966 b, 161, 129-136.

LISK, R. D. Cyclic fluctuations in sexual responsiveness in the male rat. Journal of Experimental Zoology, 1969, 171, 313-320.

OHRBACH, J. Spontaneous ejaculation in the rat. Science, 1961, 134, 1072-1073.

OHRBACH, J., MILLER, M., BILLIMORIA, A., \& SOLHKHAH, N. Spontaneous seminal ejaculation and genital grooming in rats. Brain Research, 1967, 5, 520-523.

WADE, G. N., \& ZUCKER, I. Taste preferences of female rats: Modification by neonatal hormones, food deprivation, and prior experience. Physiology \& Behavior, 1969, 4, 935-943.

WHALEN, R. E. Differentiation of the neural meshanisms which control gonadotropin secretion and sexual behavior. In M. Diamond (Ed.), Perspectives in reproduction and sexual behavior. Bloomington, Ind: Indiana University Press, 1968. Pp. 303-340. 